\title{
Faktor- Faktor yang Menyebabkan Kejadian Postpartum Blues
}

\author{
${ }^{1}$ Purwati Purwati*, ${ }^{2}$ Alfi Noviyana \\ ${ }^{1}$ Prodi Kebidanan D3, Universitas Muhammadiyah Purwokerto \\ ${ }^{2}$ Prodi Kebidanan D3, Universitas Mumhammadiyah Purwokerto \\ alfinovi13@gmail.com,watix_1006@yahoo.com
}

\begin{abstract}
Abstrak
Sekitar 70-80\% ibu pasca melahirkan mengalami gangguan mood atau perasaan, secara umum kondisi ini masih dianggap normal, dirasakan mulai 2-3 hari pasca melahirkan dan normalnya akan menghilang setelah 2 minggu post partum. Tujuan penelitian ini adalah untk mengetaui factor-faktor penyebab munculnya tanda gejala dari postpartum blues. Metode penelitian ini menggunakan kualitatif melalui pendekatan fenomenologi dengan pengambilan populasi dengan cara purposive sampling. Hasil penelitian menunjukkan Usia dan paritas tidak selalu menjadi faktor pencetus gejala postpartum blues, penyebab postpartum blues adalah khawatir dengan bayi, factor kelelahan ibu, komentar orang sekitar tentang ibu, dukungan dan kehadiran suami, adaptasi terhadap kehadiran bayi.
\end{abstract}

Kata Kunci: Penyebab, postpartum blues .

\begin{abstract}
About 70-80\% of postpartum mothers experience mood or feeling disorders. In general, this condition is still considered normal, felt from 2-3 days after delivery and normally disappears after 2 weeks post partum. The purpose of this study was to determine the factors that cause the symptoms of postpartum blues to appear. This research method used qualitative through a phenomenological approach by taking the population by means of purposive sampling. The results showed that age and parity did not always trigger the symptoms of postpartum blues, the causes of postpartum blues were worrying about the baby, maternal fatigue, comments from people around the mother, husband's support and presence, adaptation to the baby's presence.
\end{abstract}

Keywords: Causes, postpartum blues

\section{PENDAHULUAN}

Merujuk dari definisinya, post partum adalah waktu setelah melahirkan sampai enam minggu sehingga fungsi organ reproduksi kembali normal. Dalam periode postpartum tersebut seorang wanita pasca melahirkan akan mengalami adaptasi baik secara fisik maupun psikisnya. Pada adaptasi psikologis seorang wanita akan mengalami penyesuaian terhadap perannya sebagai orang tua (ibu). Sekitar 70-80 \% ibu pasca melahirkan mengalami gangguan mood atau perasaan, secara umum kondisi ini masih dianggap normal, dirasakan mulai 2-3 hari pasca melahirkan dan normalnya akan menghilang setelah 2 minggu post partum. Kondisi demikian sering disebut dengan post partum blues, maternity blues atau baby blues (Machmudah, 2015). Wanita dengan post partum blues akan menunjukkan gejala seperti sering menangis, mudah merasa cemas, mudah tersinggung, sensitif, kurang konsentrasi, mudah stres, merasa rapuh dan dan tidak berdaya, gelisah dan mengalami gangguan tidur (APA, 2013).

Seringkali ibu yang mengalami postpartum blues berkembang lebih lama dan lebih berat intensitasnya. ibu mengalami kesedihan yang mendalam dan merasa tidak berharga, sehingga merasa terganggu dalam melakukan aktivias seharihari, sekitar $15 \%$ dari ibu-ibu pasca melahirkan mengalami Postpartum Depression (depresi postpartum) yang merupakan kelanjutan dari postpartum blues yang tidak tertangani. Dampak dari depresi postpartum ibu akan mengalami depresi yang berkepanjangan dan semakin berat hingga berkeinginan untuk melukai bayi atau diri sendiri (MHI, 2020).

Sistem dukungan yang kuat dan konsisten merupakan faktor utama keberhasilan bagi ibu postpartum untuk dapat melewati postpartum blues. Sistem dukungan ini dapat dilakukan oleh orang terdekat seperti suami, orang tua dan dapat dilakukan jga oleh tenaga kesehatan.

Tujuan penelitian ini adalah untk mengetaui factor-faktor penyebab munculnya tanda gejala dari postpartum blues sehingga tanda gejala tersebut dapat diatasi. Hal ini dapat membantu ibu postpartum mengatasi tanda gejala tersebut sehingga depresi postpartum tidak terjadi.

\section{TINJAUAN PUSTAKA}

Postpartum blues adalah kondisi yag normal terjadi, begitu pula ibu sendiri juga tidak menyadari bahwa dirinya sedang mengalami postpartum blues. Kematangan dan kesiapan ibu menjadi faktor utama supaya ibu tidak mengalami stress yang verlanjut pada baby blues syndrome, kerena ibu yang memiliki kematangan dan kesiapan akan berhasil mengatasi stres setelah persalinan. (Ningrum, 2017). 
Penyebab postpartum blues belum diketahui secara pasti namun diduga beberapa faktor diantaranya perubahan hormonal yang draktis pasca melahirkan, mempengaruhi zat-zat kimia di otak yang mengatur mood, sehingga perasaan ibu menjadi terganggu. Selain itu faktor kelelahan setelah melahirkan dan menyusui juga dapat menyebabkan perubahan rutinitas karena merawat bayi juga memperberat kondisi ibu, diperparah dengan kurangnya dukungan suami, keluarga dan lingkungan sekitar kepada ibu dalam melawati masa adaptasi psikologis post partum tersebut (MHI, 2020).

Bantuan dari suami dan keluarga sangat berpengaruh dalam keberhasilan ibu agar postpartum blues tidak berkembang menjadi kondisi yang lebih berat seperti depresi postpartum . Hal-hal kecil dan menyenangkan dapat membantu ibu dalam mengurangi stress pasca persalinan seperti bercerita dan mengungkapkan perasaan pada suami tentang apa yang diinginkan ibu, mencari suasana baru, melakukan aktivitas seharihari sesuai kemampuan, olah raga dan relaksasi , segera istirahat ketika bayi tidur, mengkonsumsi makanan sehat, serta yang paling penting menanamkan pemikiran positif yang sesuai realita bahwa kehadiran seorang bayi bukanlah sebuah hal yang harus ditakuti dan di cemaskan. Penelitian Girsang dkk (2015) mengungkapkan bahwa pemberian psikoedukasi pada ibu post partum dapat menurunkan angka postpartum blues maupun depresi postpartum. Selain psikoedukasi, beberapa alternatif yang terbukti menurunkan postpartum blues diantaranya adalah dukungan sosial pada ibu melalui bounding attachment atau skin to skin contact antara ibu dan bayi pasca persalinan, kontak kulit 6 jam setiap hari selama 1 minggu dapat menurunkan post partum blues tanpa obat ( Bigelow, 2012) .

\section{METODE}

Metode penelitian ini menggunakan kualitatif melalui pendekatan fenomenologi dengan pengambilan populasi dengan cara purposive sampling (Sulaiman, 2015). Kriteria sampel ibu postpartum dan ibu dengan anak usia dibawah 1 tahun. Jumlah responden penelitian ini adalah 10 orang terdiri dari 6 responden utama dan 6 responden pendukung. Triangulasi yang digunakan pada penelitian ini adalah triangulasi teoritis.

Sebelum melalukan wawancara, peneliti melakukan kunjungan rumah sebanyak 1 kali untuk perijinan sekaligus observasi keadaan lingkungan rumah. Peneliti mengambil data dengan cara wawancara melalui media whatsapp dikarenakan situasi pandemi untuk menghindari kontak erat dan terlalu lama dengan responden.
Penelitian dilakukan di wilayah kerja Puekesmas 1 Sokaraja. Penelitian ini dilaksanakan pada bulan Oktober sampaii Desember 2020.

\section{HASIL DAN PEMBAHASAN}

Karakteristik Responden terdiri dan 6 ibu Postpartum. Rata-rata umur responden 22-40 tahun. Responden terdiri dari 6 orang ibu postpartum dengan anak lebih dari 1 dan anak terakhir kurang dari 1 tahun sejumlah 4 orang, 2 ibu postpartum dengan 1 anak usia kurang dari 1 tahun. 5 orang responden pendukung yaitu 6 orang suami dari responden utama, 1 orang responden pendukung yaitu saudara dari responden utama. Status pekerjaan responden utama 2 orang ibu rumah tangga dan 4 orang pekerja perkantoran.

Postpartum blues merupakan keadaan norma yang sering terjadi pascamelahirkan dengan tanda gejala sering menagis, mudah cemas, sensitive, mudah tersinggung, kurang konsentrasi, mudah stress, merasa rapuh dan tidak berdaya, merasa bersalah, merasa gelisah, gangguan tidur dan merasa kesepian. Hasil penelitian menunjukan bahwa tidak semua tanda gejala postpartum blues diatas muncul pada ibu postpartum, seperti pernyataan responden dibawah ini :

“Cemas" RU 1

"Merasa rapuh tak berdaya, sering menangis, merasa sendiri, mudah tersinggung dan sensitive "RU 2

"Sering menangis, cemas, sensitif, stress, gelisah, gangguan tidur” RU 3

"merasa cemas, mudah tersinggung (sensitif), kurang konsentrasi, mudah stres, merasa gelisah, gangguan tidur" RU 4

"kurang konsentrasi dan kurang tidur" RU 5

"merasa sedih, mudah tersinggung, merasa sendirian” RU 6

Postpartum blues berdasarkan hasil penelitian secara umum disebabkan sebagai berikut khawatir dengan bayi, factor kelelahan ibu, komentar orang sekitar tentang ibu, dukungan dan kehadiran suami, adaptasi terhadap kehadiran bayi. Hal tersebut didukung dari hasil wawancara sebagai berikut :

"Cemas khawatir bayi sakit,. Khawatir apa yang bayi mau ibu tidak paham sehingga bayi rewel. Lalu Nangis pas anak sakit",

RU 1

"Saat banyak saudara nginap dirumah, saat rumah berantakan dan rame

Komentar dari berbagai pihak contoh mertua , saudara, teman" RU 2

"Saat banyak saudara nginapdirumah, saat rumah berantakan dan rame.

Komentar dari berbagai pihak contoh mertua, saudara, teman"

RU 3

"Mungkin karena anak pertama jadi merasa belum berpengalaman mi, Merasa sendirian 
mi...merasa apa-apa sendiri dan tergantung seberapa besar partisipasi suami dalam mengurus anak" RU 3

"ada perubahan disikapnya, kalo saya cuek atau telat pulang” RP 4

Untuk mengatasi tanda gejala yang muncul, setiap responden mempunyai cara masing-masing seperti pernyataan dibawah ini :

"Tiduran sama bayi, Ya kadang ngemil atau buka hape” RU 2

"Berusaha menghibur diri tapi lebih banyak sharing sama temen, misal nonton tv, jalanjalan ke lingkungan rumah, ngobrol dengan tetangga gitu” RU 3

"Saya cenderung diem, mbatin aja kadang si cerita ke suami... kalau nangis pernah tapi gak sering bu, biasayna Lebih ke istirahat si bu, pas kebetulan ada ibu... jadi lebih ke tidur, atau diperbanyak asupan biar asinya lancar" RU 4

Ibu postpartum memerlukan dukungan dari suami agar tanda gejala postpartum blues bisa tertangani dan tidak berlanjut. Hasil wawancara menyatakan :

"Support selalu.. dengan siap siaga" RU 1

"suami Ngga pernah tau..aq diam aja soalnya, dukungannya ya Memenuhi keinginan $k u$, seperti beli makan apa gitu, pijat oksitosin seperti yang diajarkan bu bidan, sesekali menghibur dengan bilang sabar ya" RU 2

"Sikapnya sedikit perhatian, minta di beliin apa di beliin, trs lebih ngertiin bu” RU 3

"Menjadi pendengar setia bu, disisi lain juga ngasi perhatian lebih $n$ nenangin... mulai ikut belajar merawat debay juga yang tadinya belum bias jadi bias gentian ngurusnya" RU 4

\section{PEMBAHASAN}

Karakkteristik responden menunjukan usia yang bervariasi antara umur 22 tahun-40 tahun, dimana menurut teori usia resiko tinggi postpartum blues 20 th $\leq$ dan lebih dari $\geq 40$ th. Usia merupakan faktor pencetus terjadinya postpartum blues (Yulistia, 2018; Ningrum, 2018). Penelitian ini menunjukkan pada 22 th-40 th mengalami tanda gejala postpartum blues. Menurut Yunitasari (2020) postpartum blues dapat terjadi di semua usia pada ibu postpartum, tetapi lebih beresiko pada usia kurang dri 20 than dan lebih dari 35 tahun.

Tanda gejala yang muncul pada postpartum blues diantaranya sering menagis, mudah cemas, sensitive, mudah tersinggung, kurang konsentrasi, mudah stress, merasa rapuh dan tidak berdaya, merasa bersalah, merasa gelisah, gangguan tidur dan merasa kesepian, (MHI, 2020). Postpartum blues merupakan keadaan normal yang sering terjadi pascamelahirkan dengan tanda gejala berdasarakan hasil penelitian ini adalah sering menagis, mudah cemas, sensitive, mudah tersinggung, kurang konsentrasi, mudah stress, merasa rapuh dan tidak berdaya, merasa bersalah, merasa gelisah, gangguan tidur dan merasa kesepian. Hasil penelitian menunjukan bahwa tidak semua responden mengalami tanda gejala postpartum blues yang sama, tetapi pada dasaranya setiap ibu postpartum mengalami beberapa tanda gejala postpartum blues. Ibu postpartum dengan anak pertama mengalami tanda gejala postpartum blues, sesuai dengan hasil analisis literature review Yunitasari (2020) bahwa primipara lebih beresiko mengalami postpartum blues dari pada ibu multipara. Hal ini dipicu karena ibu dengan anak pertama belum mempunyai pengalaman dalam merawat bayi. Pada penelitian ini juga ditemukan bahwa ibu dengan anak pertama kesulitan dalam merawat bayi, dan sering mengalami tanda gejala postpartum blues, ini sesuai dengan penelitian yang dilakukan oleh Macmudah (2015) bahwa ibu dengan postpartum blues akan kesulitan merawat bayi dan menyusui kurang optimal. Sehingga diperlukan dukungan orang bterdekat untuk perawatan bayi.

Hasil penelitian postpartum blues disebabkan sebagai berikut khawatir dengan bayi, factor kelelahan ibu, komentar orang sekitar tentang ibu, dukungan dan kehadiran suami, adaptasi terhadap kehadiran bayi. Menurut Ningrum (2017) faktor yang berhubungan dengan postpartum blues diantaranya penyesuaian diri, coping stress dan dukungan sosial. Seorang ibu pasca melahirkan akan mengalami perubahan pada dirinya baikl secara fisik maupun psikologis. Ibu pasca melqahirkan secara alami akan menyesuaikan diri dengan kondisinya, jika penyesuaian diri tidak ada kendala maka ibu kemngkinan kecil mengalami gejala postpartum blues. Perubahan dan penyesuaian ini memerlukan dukungan dari orang terdekat dan lingkungan sekitarnya. Tingkat stress, cemas dan depresi menurun jika ada interaksi antara ibu postpartum dengan lingkngan sekitarnya (Hoffenar, dkk, 2010). Dukungan suami sangat diperlukan untuk mengatasi gejalka postpartum blues pada ibu selain itu keluarga dan orang terdekat dengan ibu postpartum juga berperan besar dalm mengatasi dan timbulnya gejala postpartum blues.

\section{KESIMPULAN}

Postpartum blues merupakan keadaan dimana ibu menaglami perubahan psikologis yang sering muncul pada ibu pasca melahirkan. Usia dan paritas tidak selalu menjadi faktor pencetus gejala postpartum blues. Postpartum blues dapat diatasi dengan melibatkan suami, keluarga dan lingkungan sekitar melalui dukungan pada ibu postpartum.

Peningkatan pengetahuan tentang perubahan psikologis perlu diberikan oleh tenaga kesehatan khususnya tentang postpartum blues sehingga calon 
ibu lebih siap dalam perubahan menjadi peran seorang ibu untuk bayinya.

\section{DAFTAR PUSTAKA}

American Psychiatric Assocition (2013). Diagnostic and statistical manual of mental disorder $\left(5^{\text {th }}\right.$ edn), VA : Marecan Psychiatric Publishing Arlington.

Bigelow, A., Power, M., MacLellan- Peters, J., Alex, M., \& McDonald, C. (2012). Effect of mother/infant skinto- skin contact on postpartum depressive symptoms and maternal physiological stress. Journal of Obstetric, Gynecologic \& Neonatal Nursing, 41(3), 369-382.

Bina Melvia Girsang, Miranda Novalina, Jaji (2015) Pengaruh Psikoedukasi terhadap tingkat postpartum blues ibu Primipara berusia remaja, Jurnal Keperawatan Soedirman Vol 10 (2) : 114 -120.
Hoffenar, P.J., Balen, V.F., \& Hermanns, J. (2010). The Impact of Having a Baby on the Level a Content of Woman's Well-being, Soc India Res, 9, 279-295

Machmudah 2015 Gangguan Psikologis pada Ibu Postpartum; Postpartum Blues. Jurnal Keperwatan maternitas Vol 3(2) : 118-125)

Mother Hope Indonesia, Postpartum Blues Syndrome Jakarta, MHI

Prasetya Ningrum (2017) Faktor -faktor psikologis yang Memengaruhi Postpartum Blues PSYMPATHIC Jurnal Ilmiah Psikologi Vol 4(2) : 205-218.

Yunitasari E., Suryani. Postpartum blues sebuah tinjaun literature. Wellness and Healthy Magazine. Vol 2. Issue 2. Agustus 2020. 303307

Yuistia, Yuni (2018). Young age pregnancy and postpartum blues incidences Healty Polytechnic of Health Ministri 